\title{
The effect of behavioral rehearsal technique through group counseling for overcoming social anxiety of students
}

\author{
Abdul Saman $^{\left.1^{*}\right)}$, Muh Ilham Bakhtiar ${ }^{2}$ \\ ${ }^{1}$ Universitas Negeri Makasar, Indonesia. \\ ${ }^{2}$ STKIP Andi Matappa, Indonesia. \\ ${ }^{*}$ Corresponding author, $\supseteqq$ e-mail: abdulsaman@unm.ac.id
}

\begin{abstract}
This research examined the influence of group counseling using behavioral rehearsal techniques to overcome students' social anxiety. This research used the quantitative method with a quasi-experimental design namely Matching-Only Design. The study involved 30 students for the control group and 30 students for the experimental group selected through purposive sampling. Data were collected using a questionnaire that had been validated. They were then analyzed using normality testing, homogeneity, data nominality testing, gain score and hypothesis testing. The findings of this research indicated that group counseling through behavioral rehearsal techniques could overcome the problem of social anxiety experienced by students. In the pretest, the research showed that the social anxiety level of students in the experimental group was in the high category, and the control group was in the medium category. While the posttests of both experimental and control groups were in the very low category. Behavioral rehearsal techniques should be informational and practical in the development of knowledge, especially in dealing with the problems of social anxiety.
\end{abstract}

Keywords: Social anxiety, group counseling, behavioral rehearsal.

How to Cite: Saman, A., \& Bakhtiar, M. (2020). The effect of behavioral rehearsal technique through group counseling for overcoming social anxiety of students. COUNS-EDU: The International Journal of Counseling and Education, 5(1), 15-22. DOI: http:// doi.org/10.23916/0020200525110

This is an open access article distributed under the Creative Commons Attribution License, which permits unrestricted use distribution, and reproduction in any medium, provided the original work is properly cited. C2020 by author.

\section{Introduction}

Adolescents naturally find it challenging to involve in their social life ( (Valeria Ivaniushina, 2016); (Shier, Gouthro, \& Goias, 2018). The university students as members of adolescents groups and social individuals, in fulfilling their needs, undertake social interactions within their environment (Mutahari, 2016); (Wang, Tian, \& Huebner, 2019), family, school, and societies (Bakhtiar, 2015); (Bakhtiar, Saman, \& Aryani, 2017). Adolescents do social interaction as a part of their development in the search for identity (Wirawan, Jufri, \& Anto Patak, 2018). However, not all adolescents can comfortably interact with their social environment. Many individuals tend to be worry and fear the negative perception of the environment. Hofmann and DiBartolo (2014) revealed that social anxiety mostly occurs in adolescence. The anxiety of adolescent students occurs when they meet new friends, new teachers, or new school rules. Some students are also embarrassed when interacting with others, and often students are embarrassed just to speak in front of the class as they are afraid to be observed, cursed, or criticized by others (Bakhtiar \& Rahmatia, 2018).

During adolescence, the physical, cognitive, and behavioral hallmarks of the social anxiety disorder (SAD) often start to appear (Alfano \& Beidel, 2011). The social anxiety faced by individuals is usually due to their movement into a new environment. Social anxiety, characterized by significant discomfort and 


\section{COUNS-EDU}

Vol.5, No.1, 2020

avoidance of social and/or performance situations (APA, 2017) is one of the most common mental disorders in children and adolescents. Social anxiety disorder starts at the age of 5 and peaks around the age of 12 (RC, et al., 2005). When untreated, it can run a chronic course into adolescence and eventually adulthood (KA, SE, IR, \& MB, 2003). There is a rapid change in early adolescence that usually occurs between ten and thirteen years old (Moshman, 2011). In this case, physically, there are significant changes along with puberty.

Rapid changes occur in early adolescence and usually, occur between the ages of 10-13 (Romano, Moscovitch, Ma, \& Huppert, 2019). In this case, physically, there are some major changes along with puberty. Then, cognitively, there is a fundamental change in intellectual ability (Moshman, 2011). The level of mental illness that is increasingly rampant simultaneously with a social anxiety disorder is called social phobia (Stein \& Stein, 2008). It is characterized by excessive fear of being humiliated or embarrassed in social situations (APA, 2017) and is often chronic and severely debilitating if untreated (B.F. Grant, 2005). Social anxiety disorder shows high comorbidity with other diagnoses, such as depression, (Goldstein-Piekarski, Williams, \& Humphreys, 2016). This is an anxiety disorder leading a person to feel the excessive fear of being in a social environment for no obvious reason(Albano \& Hayward, 2004; Ledley et al., 2008). This anxiety is realized arising from the fear of being observed as others might give a critique. Symptoms experienced by people with this disorder include feeling anxious when in the crowd; avoiding the crowd or social environment, having physical symptoms such as fast heartbeat, sweating, trembling, excessive shyness, muscle tension, abdominal pain, and even diarrhea (Bakhtiar, Saman, \& Aryani, 2017). This anxiety is caused by individual problem behavior so that proper handling is needed in the form of behavior change. Behavior change aims to change observable and measurable human behaviors (Sheeran, Klein, \& Rothman, 2017). The changes are selected according to the problems faced by the student. Changing behavior is a behavioral rehearsal that is one of the behavior therapy techniques (Beidas, Cross, \& Dorsey, 2014; Wright, Brown, Thase, \& Basco, 2017).

Several studies have examined social problem-solving in the context of social anxiety. Research overcoming social anxiety used Cognitive Behavior Therapy (CBT) approach using diary checklist (Duana \& Hadjam, 2012). Then another study handled anxiety through CBT by educating sufferers (Fitri, 2017) but did not apply counseling intervention, then other studies only diagnosed anxiety levels and dissect the effects of social anxiety. But also did not use intervention techniques with training focused on social problems encountered, in this case, the behavioral rehearsal.

Behavioral rehearsal is one of many techniques derived from behavioral therapy (Hecker \& Thorpe, 2015). This behavioral therapy technique was initially called behavioral psychodrama (Blatner, 2003). However, the more commonly used term is rehearsal behavior (exercise behavior) that is usually applied to clients who need full rehearsal behavior in the form of exercise. Behavioral rehearsal techniques are applied through role-playing that allows the client to learn a new type of behavior in addition to the ones available in the counseling situation. Rehearsal behavior incorporates several vital components: imitating behavior, receiving feedback from counselors, and often practicing/training the target behavior (Erford, 2014). Collaboration in a group aims at providing a shared learning experience in handling such anxiety problems. Walsh (2002) revealed that a behavioral rehearsal technique is useful when dealing with people who experience social anxiety. Behavioral rehearsal is one of the group counseling types. Counseling, is a professional assistance that is carried out through various procedures, one of them through group learning. Group counseling can give individuals a variety of group experiences that help them to learn efficiently, be more tolerant facing stress and anxiety, and find satisfaction in working and living with others (Corey, 2015). The behavior might positively affect the classroom environment. A rehearsal behavioral technique in the form of group counseling that provides a learning experience to change student behaviors is the subject of this study. Therefore, this research aimed at describing student social anxiety before and after applying group counseling with the Behavioral Rehearsal approach. Also, this research examined the influence of group counseling through the Behavioral Rehearsal approach to overcome student social anxiety.

\section{Method}

The type of this research was quantitative with a quasi-experimental design that examined the influence of group counseling through rehearsal behavioral approaches to overcome students' social 
anxiety. Experimental research is a method used to examine the effect of a particular treatment on subjects under controlled conditions (Creswell, 2012; Fraenkel \& Wallen, 2009). It relies on treatments applied to the experimental group and is subjected to specific treatments with controllable conditions.

Fraenkel and Wallen (2009) argued that the use of random assignment is not categorized as a quasiexperimental design. Therefore, to employ this design, the other techniques were used to control the internal validity. This research used Matching-Only Design. This study involved 30 students for the control group and 30 students for the experimental group selected through purposive sampling. Data were collected using a questionnaire that had been validated. The data were analyzed using normality testing, homogeneity,gain score and hypothesis testing. The purpose of the questionnaire was to obtain an overview of the social anxiety level experienced by the experimental students before receiving counseling through the behavioral rehearsal approach. Subjects for experimental and control groups were determined according to definite variables. The variable was the behavior training technique given to the experimental group. The experimental group was treated with the behavioral rehearsal to social anxiety while the control group was not. The matching-only control group design using pretest and post-test can be seen in table 1:

Table 1. The matching-only pretest-posttest control group design

\begin{tabular}{lllll}
\hline Treatment Group & $\mathrm{M}$ & $\mathrm{O}$ & $\mathrm{X}$ & $\mathrm{O}$ \\
\hline Control Group & $\mathrm{M}$ & $\mathrm{O}$ & $\mathrm{O}$ \\
\hline
\end{tabular}

The $\mathrm{M}$ in table above means that subjects of both groups were not randomly determined. $\mathrm{X}$ refers to the treatment (behavioral rehearsal) applied on the experimental group. The research procedures included: planning, pre-test, implementing behavioral rehearsal and post-test. Following is the more detailed schema:

- Determination of experimental subjects.

- Distribution of pretest on the research subjects related to behavioral rehearsal techniques., Implementation of behavioral rehearsal on the subjects of the study. The treatments were given for three times (three meetings). At each meeting, students were taught about techniques to practice behavior through deep breathing exercises. Each student was challenged to do practice at home.

- Distribution of post-test on the research subjects.

- Analysis of the data about the results of the activities.

Thirty students were given treatment and the same numbers of other vocational secondary students were controlled. The students who were registered were identified as having high social anxiety. The data collection in this study was conducted using a validated questionnaire.

\section{Results and Discussion}

Implementation of the treatment which in this case was the behavioral rehearsal approach was addressed to vocational secondary students who had agreed upon meeting time to overcome their social anxiety. During the treatment, the researcher became the program coordinator. The treatment was performed during 3 (three) sessions. The research data were obtained from the questionnaire measuring the students' social anxiety in the experimental and control groups. The following table presents pretest and posttest data measuring the results of the implementation of counseling approach behavioral rehearsal in overcoming social anxiety of students studying at vocational secondary school.

Based on the pretest, the medium and the low categories of social anxiety show the biggest percentage which was 30 or there were 8 students in each category. One fifth (6) students had a high level of anxiety. Only 10 percent of students in the very high category and another $10 \%$ were in the very low category. However, after treated with the group-counseling using the behavioral rehearsal approach through three stages, students' anxiety showed significant changes. More than half of the students experienced very low anxiety and forty-four percent of them had low social anxiety indicated the significant decrease in social anxiety level in general. 
Table 2. Data on the social anxiety level of experimental group students treated with group counseling through behavioral rehearsal approach according to the post-test and pretest

\begin{tabular}{|c|c|c|c|c|c|}
\hline \multirow{3}{*}{ Intervals } & \multirow{3}{*}{ Activities } & \multicolumn{4}{|c|}{ Experimental group } \\
\hline & & \multicolumn{2}{|c|}{ Pretest } & \multicolumn{2}{|l|}{ Posttest } \\
\hline & & Frequencies & Percentages & Frequencies & Percentages \\
\hline $61-74$ & Very high & 4 & 10 & 0 & 0 \\
\hline $47-60$ & High & 6 & 20 & 0 & 0 \\
\hline $33-46$ & Medium & 8 & 30 & 0 & 0 \\
\hline $19-32$ & Low & 8 & 30 & 14 & 44 \\
\hline $5-18$ & Very low & 4 & 10 & 16 & 55 \\
\hline & tal & 30 & 100 & 30 & 100 \\
\hline
\end{tabular}

The following table also presents data of students' anxiety levels in the control group based on the pretest and post-test conducted simultaneously to the experimental group. The data shows the changes in students' levels of social anxiety without treatment.

Table 3. Data on the social anxiety level of students according to pretest and posttest in the control group

\begin{tabular}{|c|c|c|c|c|c|}
\hline \multirow{3}{*}{ Intervals } & \multirow{3}{*}{ Activities } & \multicolumn{4}{|c|}{ Control Group } \\
\hline & & \multicolumn{2}{|c|}{ Pretest } & \multicolumn{2}{|c|}{ Posttest } \\
\hline & & Frequencies & Percentages & Frequencies & Frequencies \\
\hline $61-74$ & Very high & 0 & 0 & 0 & 0 \\
\hline $47-60$ & High & 1 & 4 & 0 & 0 \\
\hline $33-46$ & Medium & 13 & 42 & 12 & 40 \\
\hline $19-32$ & Low & 14 & 46 & 15 & 55 \\
\hline $5-18$ & Very low & 2 & 8 & 3 & 5 \\
\hline Total & & 30 & $100 \%$ & 30 & $100 \%$ \\
\hline
\end{tabular}

The social anxiety levels of students in the control group according to the pretest were majorly in the medium and low category as $42 \%$ and $46 \%$ of students respectively in those groups. Only 1 student $(4 \%)$ had a high anxiety rate and two students experienced a very low anxiety level. None of them $(0 \%)$ in the very high category. However, when the postest conducted, the results showed insignificant changes. Twelve students (40\%) were in the medium category, just above half of the students (55\%) had low social anxiety, and only $5 \%$ were in the very low group.

Table 4. The comparison of the pretest, posttest, dan gain score of experimental and control groups

\begin{tabular}{lllll}
\hline Data Type & Group & Mean & Interval & Classification \\
\hline \multirow{2}{*}{ Pretest } & Experiment & 37.73 & $47-60$ & High \\
\cline { 2 - 5 } & Control & 33 & $33-46$ & Medium \\
\hline \multirow{2}{*}{ Posttest } & Experiment & 18 & $5-18$ & Very low \\
\cline { 2 - 5 } & Control & 30,02 & $19-32$ & Low \\
\hline
\end{tabular}

It can be seen that the level of experimented students' social anxiety was in the high category and the students in the control group were categorized in the medium level according to the pretest. While the posttest of the experimental group was in the very low category and the control group was in a low category. Hence, the problem of social anxiety experienced by the students before and after the treatment changed significantly.

\section{Inferential statistics}

The inferential statistics in this research aimed at examining the influence of a behavioral rehearsal approach to overcoming student social anxiety. The hypothesis of this research states that there is an 
influence of behavioral rehearsal approach on student social anxiety in vocational secondary school." If $\mathrm{H} 1$ is accepted and Ho is rejected, there is a significant influence of the method to overcome students' anxiety. While, if Ho accepted and $\mathrm{H} 1$ is refused, then there is no significant influence of the method in overcoming students' anxiety. The data analysis according to the t-test of student anxiety level areas are as follows:

Table 5. Paired sample statistics

\begin{tabular}{llllcc}
\hline \multicolumn{2}{l}{ Paired Samples Statistics } & & & & \\
\hline & Mean & $\mathrm{N}$ & Std. Deviation & Std. Error Mean \\
\hline \multirow{2}{*}{ Pair 1} & pretest & 37.73 & 30 & 18.132 & 3.310 \\
\cline { 2 - 6 } & posttest & 19.07 & 30 & 7.575 & 1.383 \\
\hline
\end{tabular}

Table 5 presents the statistical result data of the implementation of techniques obtained from the pretest and posttest questionnaires. The Mean score of the pretest was 37.73 while the posttest was 19.07. Interestingly, the posttest showed a smaller mean score than the pretest. In other words, the posttest Mean score showed a drastic decrease or significant changes in students' social anxiety. It indicates that group counseling with behavioral rehearsal is very useful to overcome the social anxiety of students at the vocational secondary school.

Table 6. Paired sample test

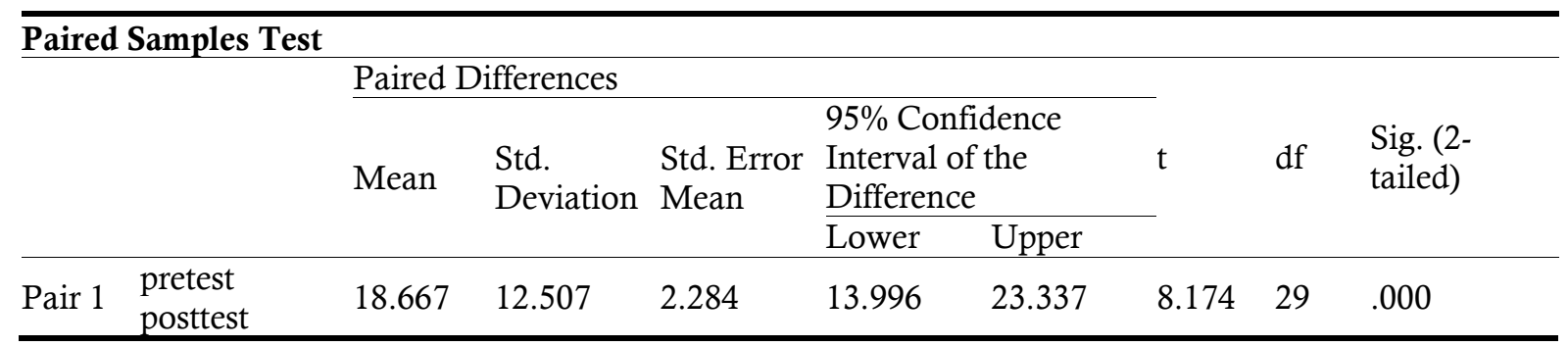

In testing the hypotheses based on the data gathered from the pretest and posttest distributed to students in the experimental group, it shows the sig. $=000$ which means that it was $<0.05$, thus it was regarded that the Behavioral Rehearsal technique can reduce the student anxiety. If the probability value $>$ 0.05, then $\mathrm{HO}$ (null hypothesis) is accepted and $\mathrm{Ha}$ (alternative hypothesis) is rejected while if the probability value $<0.05$ then $\mathrm{H} 0$ is rejected, but Ha is accepted (Ismail, 2018). As the t-test showed that the Sig. (2-tailed) $0,000<0.05$, the use of Rehearsal Behavioral techniques can overcome student anxiety.

The data in this research indicated the ability of group counseling applying behavioral rehearsal techniques to overcome the students' social anxiety. This technique was performed through counseling under set situations or group settings with various procedures (Brown, 1994). Counseling means helping people professionally with a variety of procedures, one of them through group counseling. However, the success of counseling also depends on the experience of the counselor (Kurtylmaz, 2015).

This rehearsal is an exercise to change the individual's behavior (Beidas et al., 2014). Behavioral rehearsal is applied through role-playing that allows the client to learn a new type of behavior outside the counseling situation. Behavioral rehearsal incorporates several key components: imitating behavior, receiving feedback from counselors, and practicing/training the target behavior (Erford, 2014). The activities are performed collaboratively in one group, to provide a shared learning experience in handling anxiety problems.

This research showed the significant changes in the social anxiety level experienced by students of the vocational secondary school after the implementation of counseling. Previously, the behavioral rehearsal was in the high category. Problems faced by students included feeling anxious in a new situation and when facing a school exam; feeling tense in certain circumstances, feeling fear of their mind, having 
difficulty concentrating on the lessons, having a poor memory, and frequently feeling sad. Social anxiety disorders affect emotions and behavior (Albano \& Hayward, 2004; Beidas et al., 2014; Ledley et al., 2008; Muller et al., 2005; Raj \& Sheehan, 2001; Schneier, 2006; Stein \& Stein, 2008; Swinson, 2005; Turk et al., 2001). Students will be difficult to follow the lessons and tend to feel threatened in school. Some social anxiety disorders are indicated by excessive fear when interacting with strangers, fear to be judged, and worry to be embarrassed. Social anxiety disorder is a chronic mental health condition, but treatments such as psychological counseling or various coping skills can help people to build confidence and improve the ability to interact with others.

The behavioral rehearsal technique given to students experiencing anxiety through group counseling reflected significant changes. It can be seen in table 5 describing statistical data obtained from the pretest and posttest questionnaires measuring the effect of the implementation of techniques. The mean score of the pretest was 37.73 while the posttest showed the mean value of 19.07. This showed that the influence of behavioral rehearsal techniques in overcoming students' social anxiety is significant. Then the hypothesis test was performed according to statistical analysis of data obtained from the pretest and posttest questionnaire. As depicted in table 6, the value of $t$ was 8.174 with a sig of 0.000 (meaning lower than 0.05). The posttest score that was smaller than the pretest indicated a drastic decrease or significant changes in the social anxiety level. This showed that by providing group counseling with behavioral rehearsal, the technique is very effective to overcome the social anxiety of the vocational secondary school students. These results are in line with (Fitriana, Firman, \& Daharnis, 2018) They showed that CBT counseling group setting is effective in overcoming student social anxiety. The results of this study can be used as one of the strategies in overcoming the students' social anxiety. Zakiyah's study (2014) about overcoming anxiety and depression through CBT, showed that CBT is effective in reducing anxiety and depression. Social Anxiety in Obese Adolescent Girls was successfully overcome with CBT group counseling (Duana \& Hadjam, 2012) and the patient's sleep quality due to severe anxiety could be improved through relaxation exercises (Sudiarto, Suwondo, \& Nurrudin, 2015).

Behavioral rehearsal as part of CBT has some advantages like the exercises by imitating deep breathing behavior can be done in a group under set situations, and the assignments can be conducted independently so that students can also practice do it at home with a more comfortable and relaxed atmosphere. (Maharani \& Hayati, 2020).

Breathing exercise is also usually practiced through yoga to overcome the anxiety of pregnant women (Maharani \& Hayati, 2020). Besides that, deep breathing intervention can ameliorate the 'tension anxiety 'and fatigue in patients with gynecological cancer undergoing adjuvant chemotherapy (Hayama \& Inoue, 2012).

Finally, the behavioral rehearsal technique through deep breathing exercises can be a solution for students in overcoming the problem of social anxiety. However, teacher guidance and counseling had the main role in overcoming social anxiety through the implementation of the behavioral rehearsal technique.

\section{Conclusion}

The implementation of behavioral rehearsal techniques in a group setting was conducted through exercise or warming up breathing during 3 (three) sessions. In the pretest, the research showed that the social anxiety level of students in the experimental group was in the high category, and the control group was in the medium category. While the posttest of the experimental group was in the very low category and that of the control group was in a low category. Thus, the social anxiety problem faced by students showed significant changes after the treatment. This research indicated that there are significant differences before and after the application of rehearsal behavior techniques. Breathing warming up exercises to change inappropriate behavior does not only work for patients but can also overcome students' anxiety in doing social interaction at school.

For educational institutions, behavioral rehearsal techniques should be introduced especially for students experiencing social anxiety problems. Finally, the findings are expected to contribute to other 
future studies about behavioral rehearsal techniques for personal problems faced by students, especially social anxiety.

\section{References}

Alfano, C. A., \& Beidel, D. C. (2011). Social Anxiety in Adolescents and Young Adults: Translating Developmental Science Into Practice. Washington, DC: American Psychological Association.

APA. (2017). Diagnostic and statistical manual of mental disorders. 5th. Washington, DC: American Psychiatric Association.

Albano, A. M., \& Hayward, C. (2004). Social anxiety disorder. Phobic and anxiety disorders in children and adolescents: A clinician's guide to effective psychosocial and pharmacological interventions, $198-235$.

Beidas, R. S., Cross, W., \& Dorsey, S. (2014). Show me, don't tell me: Behavioral rehearsal as a training and analogue fidelity tool. Cognitive and Behavioral Practice, 21(1), 1-11.

Blatner, A. (2003). Psychodrama. Play Therapy with Adults, 34-61.

Brown, N. W. (1994). Group counseling for elementary and middle school children. Praeger.

B.F. Grant, F. S. (2005). Prevalence, correlates, and comorbidity of bipolar I disorder and axis I and II disorders: results from the National Epidemiologic Survey on alcohol and related conditions. $J$. Clin. Psychiatry, 66, 1205-1215.

Bakhtiar, M. I. (2015). Pengembangan video ice breaking sebagai media bimbingan konseling dalam meningkatkan keterampilan sosial. Jurnal Psikologi Pendidikan dan Konseling: Jurnal Kajian Psikologi Pendidikan dan Bimbingan Konseling, 1(2), 150-162.

Bakhtiar, M. I., \& Rahmatia. (2018). The Effectiveness of Group Counseling Model through The Behavioral Rehearsal Approach to Overcome Student Social Anxiety. Journal of Education, Teaching and Learning, 3(2), 354-360. doi:10.26737/jetl.v3i2.779

Bakhtiar, M. I., Saman, A., \& Aryani, F. (2017). Mengatasi Kecemasan Sosial Melalui Pendekatan Behavioral Rehearsal. Seminar Nasional Dies Natalis Universitas Negeri Makassar, 320-326.

Corey, G. (2015). Theory and practice of group counseling. Cengage Learning.

Creswell, J. W. (2012). Educational research: planning, conducting, and evaluating quantitative and qualitative resarch. Educational Research. Pearson.

Duana, D. A., \& Hadjam, M. N. (2012). TERAPI KOGNITIF PERILAKU DALAM KELOMPOK UNTUK KECEMASAN SOSIAL PADA REMAJA PUTRI DENGAN OBESITAS. Jurnal Intervensi Psikologi, 4(2), 145-160.

Erford, B. T. (2014). 40 techniques every counselor should know. Pearson Higher Ed.

Fraenkel, J. R., \& Wallen, N. E. (2009). How to design and evaluate research in education. Qualitative Research. McGraw-Hill Higher Education.

Fitri, D. (2017). EFEKTIVITAS COGNITIVE BEHAVIOR THERAPY UNTUK MENURUNKAN KECEMASAN BERBICARA DI DEPAN UMUM PADA MAHASISWA. Jurnal Psikologi, 10(1), 64-71.

Fitriana, Firman, \& Daharnis. (2018). Effectiveness of cognitive behavior therapy counseling group setting in overcoming student's social anxiety. International Conferences on Educational, Social Sciences and Technology (hal. 740-746). Padang: Universitas Negeri Padang.

Goldstein-Piekarski, A., Williams, L., \& Humphreys, K. (2016). A trans-diagnostic review of anxiety disorder comorbidity and the impact of multiple exclusion criteria on studying clinical outcomes in anxiety disorders. Transl. Psychiatry, e847.

Hecker, J., \& Thorpe, G. (2015). Introduction to clinical psychology. Taylor \& Francis.

Hofmann, S. G., \& DiBartolo, P. M. (2014). Social anxiety: clinical, developmental, and social perspectives. Elsevier Science.

Hayama, Y., \& Inoue, T. (2012). The effects of deep breathing on 'tension-anxiety' and fatigue in cancer patients undergoing adjuvant chemotherapy. Complementary Therapies in Clinical Practice, 18(2), 9498. doi:10.1016/j.ctcp.2011.10.001

Ismail, H. F. (2018). Statistika untuk Penelitian Pendidikan dan Ilmu-Ilmu Sosial. Jakarta: Kencana

KA, Y., SE, B., IR, D., \& MB, K. (2003). Chronicity, relapse, and illness-Course of panic disorder, social anxiety, and generalized anxiety disorder: Findings in men and women from 8 years of follow-up. Depression and Anxiety, 30-41.

Kurtylmaz, Y. (2015). Counselor Trainees' Views on Their Forthcoming Experiences in Practicum Course. Psikolojik Danışman Adaylarının Bireyle Psikolojik Danışma Uygulaması Dersindeki Olası 
Yaşantılarına İlişkin Görüşleri., (61), 155-180.

La Greca, A. M., \& Lopez, N. (1998). Social anxiety among adolescents: Linkages with peer relations and friendships. Journal of Abnormal Child Psychology, 26(2), 83-94.

Ledley, D. R., Erwin, B. A., Heimberg, R. G., Craighead, W. E., Miklowitz, D. J., Craighead, L. W., \& Craighead, L. W. (2008). Social anxiety disorder. Psychopathology: History, Theory, and Empirical Foundations, 198-233.

Maharani, S., \& Hayati, F. (2020). Pengaruh Prenatal Gentle Yoga Terhadap Tingkat Kecemasan Ibu Hamil Menghadapi Persalinan. Jurnal Endurance : Kajian Ilmiah Problema Kesehatan, 5(1), 161-167.

Moshman, D. (2011). Adolescent rationality and development: cognition, morality, and identity, third edition. Taylor \& Francis.

Muller, J. E., Koen, L., Seedat, S., \& Stein, D. J. (2005). Social Anxiety Disorder. CNS Drugs, 19(5), 377391.

RC, K., P, B., O, D., R, J., KR, M., \& EE, W. (2005). Lifetime prevalence and age-of-onset distributions of DSM-IV Disorders in the National Comorbidity Survey Replication. Archives of General Psychiatry, 62(6), 593-605.

Romano, M., Moscovitch, D. A., Ma, R., \& Huppert, J. D. (2019). Social problem solving in social anxiety disorder. Journal of Anxiety Disorders, 68, 102152.

Raj, B. A., \& Sheehan, D. V. (2001). Social anxiety disorder. Medical Clinics of North America, 85(3), 711733.

Schneier, F. R. (2006). Social anxiety disorder. New England Journal of Medicine, 355(10), 1029-1036.

Sheeran, P., Klein, W. M. P., \& Rothman, A. J. (2017). Health behavior change: Moving from observation to intervention. Annual Review of Psychology, 68, 573-600.

Stein, M. B., \& Stein, D. J. (2008). Social anxiety disorder. The Lancet, 371(9618), 1115-1125.

Swinson, R. P. (2005). Social anxiety disorder. SAGE Publications Sage CA: Los Angeles, CA.

Shier, M. L., Gouthro, S., \& Goias, R. d. (2018). The pursuit of social capital among adolescent high school aged girls: The role of formal mentor-mentee relationships. Children and Youth Services Review, 93, 276-282. doi:10.1016/j.childyouth.2018.07.034

Sudiarto, Suwondo, A., \& Nurrudin, A. (2015). Effect of Relaxation with Changes Anxiety And Sleep Quality ICU Patient in Intensive Care Unit. Jurnal Riset Kesehatan, 4(3), 847-856.

Turk, C. L., Heimberg, R. G., \& Hope, D. A. (2001). Social anxiety disorder. Clinical Handbook of Psychological Disorders: A Step-by-Step Treatment Manual, 3, 114-153.

Valeria Ivaniushina, V. L. (2016). Academic help seeking among Russian minority and non-minority adolescents: A social capital outlook. Learning and Individual Differences, 50, 283-290. doi:10.1016/j.lindif.2016.07.016

Wang, Y., Tian, L., \& Huebner, E. S. (2019). Basic psychological needs satisfaction at school, behavioral school engagement, and academic achievement: Longitudinal reciprocal relations among elementary school students. Contemporary Educational Psychology, 56, 130-139. doi:10.1016/j.cedpsych.2019.01.003

Walsh, J. (2002). Shyness and social phobia a social work perspective on a problem in living. Health \& Social Work, 27(2), 137-144. https://doi.org/10.1093/hsw/27.2.137

Wirawan, H., Jufri, M., \& Anto Patak, A. (2018). Spiritual group training for adolescences. International Journal for Lesson and Learning Studies, 7(1), 62-74. https://doi.org/10.1108/IJLLS-10-2016-0040

Wright, J. H., Brown, G. K., Thase, M. E., \& Basco, M. R. (2017). Learning cognitive-behavior therapy: an illustrated guide. American Psychiatric Pub.

Zakiyah. (2014). Pengaruh dan Efektivitas Cognitive Behavior Therapy (CBT) Berbasis Komputer terhadap Klien Cemas dan Depresi. E-Journal Widya Kesehatan dan Lingkungan. 1.(1): 75-80. 